\title{
Size makes a difference
}

\author{
Jeppe Matthiessen*, Sisse Fagt, Anja Biltoft-Jensen, Anne Marie Beck and Lars Ovesen \\ Danish Veterinary and Food Administration, Institute of Food Safety and Nutrition, Mørkhøj Bygade 19, \\ DK-2860 Søborg, Denmark
}

Submitted 17 December 2001: Accepted 10 June 2002

\begin{abstract}
Objective: To elucidate status and trends in portion size of foods rich in fat and/or added sugars during the past decades, and to bring portion size into perspective in its role in obesity and dietary guidelines in Denmark.

Data sources: Information about portion sizes of low-fat and full-fat food items was obtained from a 4-day weighed food record (Study 1). Trends in portion sizes of commercial foods were examined by gathering information from major food manufacturers and fast food chains (Study 2). Data on intakes and sales of sugarsweetened soft drinks and confectionery were obtained through nation-wide dietary surveys and official sales statistics (Study 3).

Results: Study 1: Subjects ate and drank significantly more when they chose low-fat food and meal items (milk used as a drink, sauce and sliced cold meat), compared with their counterparts who chose food and meal items with a higher fat content. As a result, almost the same amounts of energy and fat were consumed both ways, with the exception of sliced cold meat (energy and fat) and milk (fat). Study 2: Portion sizes of commercial energy-dense foods and beverages, and fast food meals rich in fat and/ or added sugars, seem to have increased over time, and in particular in the last 10 years. Study 3: The development in portion sizes of commercial foods has been paralleled by a sharp increase of more than $50 \%$ in the sales of sugar-sweetened soft drinks and confectionery like sweets, chocolate and ice creams since the 1970s.

Conclusions: Larger portion sizes of foods low in fat and commercial energy-dense foods and beverages could be important factors in maintaining a high energy intake, causing over-consumption and enhancing the prevalence of obesity in the population. In light of this development, portion size ought to take central place in dietary guidelines and public campaigns.
\end{abstract}

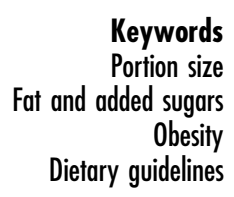

Portion size

Obesity

Dietary guidelines
In the last couple of decades, Denmark, like large parts of the world, has experienced a dramatic increase in the prevalence of overweight and obesity, especially among younger people. According to the last nation-wide dietary survey conducted in 1995, 28\% of Danish adults were classified as overweight and $8 \%$ were classified as obese ${ }^{1}$. The most likely explanation for a more than $20 \%$ increase in overweight and obesity in a 10 -year period is a changing environment promoting a surplus of food intake and physical inactivity. The increase in overweight and obesity has occurred in spite of a decrease in dietary fat intake from an average of $43 \%$ of energy in 1985 to $37 \%$ in $1995^{1}$. This phenomenon has been designated the American paradox after first being observed in the United States ${ }^{2}$. One reason may be that people have compensated for dilution in energy from fat by consuming low-fat foods ad libitum, increasing the total amount of food eaten ${ }^{3,4}$. In favour of this hypothesis, a study by Rolls and co-workers ${ }^{5}$ has demonstrated that from early childhood our food intake seems to be determined more by social, cultural and environmental factors than by hunger and satiety cues. When served larger portion sizes, both lean and overweight adults increase their food and energy intakes ${ }^{6}$. Portion sizes of energy-dense foods could also contribute to an excess energy intake by inducing passive overconsumption. Passive over-consumption refers to the excess of energy ingested without increasing the volume of food eaten. This phenomenon is especially prevalent in relation to energy-dense foods with a high fat/carbohydrate ratio, as energy from fat is less satiating than energy from carbohydrate ${ }^{7,8}$.

During recent years the number of 'super-sized' food items available in grocery stores and supermarkets has increased substantially, as has the choice of snacks, soft drinks and confectionery like sweets, chocolate and ice cream high in fat, added sugars and calories. Moreover, conventional and fast food restaurants serve larger 'value' meals, and offer all-you-can-eat buffets in the competition to get customers. The idea behind this concept is to satisfy 
consumers with more food for less money as a way to retain and expand market share ${ }^{9-13}$.

The aim of this paper is to elucidate status and trends in portion sizes of foods rich in fat and/or added sugars during the past decades, and to bring portion size into perspective in its role in obesity and dietary guidelines in Denmark. This is done by first investigating the relationship between portion size and energy and fat intakes, by comparing portions of low-fat and full-fat food items. The second step is to study whether the portion sizes of commercial foods like sugar-sweetened soft drinks, pre-packed confectionery and snacks as well as fast food meals have actually increased over time, and relate this development to data on intakes and sales.

\section{Material and methods}

\section{Study 1: Portion size of low-and full-fat food items} A 4-day weighed food record conducted by the Danish Veterinary and Food Administration in 1999 was used as data source. Participants comprised 50 children aged 4-14 years ( 26 boys and 24 girls) and 130 adults between 15 and 70 years of age ( 67 men and 63 women) from the eastern and western parts of Denmark. To ensure a reasonable basis for estimating standard portion sizes for children and adults, children were slightly over-represented in the survey compared with the distribution in the Danish population. All participants volunteered for the study. The subjects were instructed to weigh all that they ate and drank for four consecutive days (three weekdays and one weekend day). Data on age, height and weight were obtained through a self-administered questionnaire. Seventeen per cent $(n=8)$ of the children in the survey were classified as overweight according to their body mass index, but none was obese. This is slightly more than in the last nation-wide dietary survey 1995 (11\%, unpublished data). Thirty-two per cent $(n=41)$ of the adults were overweight and $13 \%(n=17)$ were obese, which is in accordance with the most recent data for the Danish population $^{14}$.

Comparisons of average portion sizes of low- and highfat foods and meal items were done for milk used as a drink (semi-skimmed vs. whole), sauce ( $<5 \%$ fat: tomato, vegetables and sweet and sour vs. $>15 \%$ fat: brown, curry, parsley, cream, béarnaise, venison and gravy), sliced cold meat (turkey/chicken vs. salami) used on bread and pork (ham/smoked saddle of pork/pork chop vs. pork roast/ sliced belly/streaky belly joint) using the weighed record (unpublished data). Milk used for porridge, cereal, etc. is not included in the data for milk. All of the food items analysed in the four categories (milk as a drink, sauce, sliced cold meat and pork) can be regarded as substitutes in a meal. Subjects are grouped according to the type of food item consumed, thus individuals who eat both lowand full-fat food items are represented in both groups. In the weighed record, the term portion size refers to amount of food weighed and eaten in a single helping.

\section{Study 2: Size of commercial foods}

Trends in portion sizes of commercial foods rich in fat and/ or added sugars were examined by obtaining information from selected major food manufacturers and fast food chains. Coca-Cola, Haribo, Frisko, Nestlé, Estrella and McDonald's provided data on sales, weight, energy and nutrient contents, and years of introduction and termination, of some of the most popular and best-selling commercial foods. Years of introduction and termination were specified as precisely as possible according to the information gathered. Information was obtained by personal communications with food manufacturers and fast food chains (marketing, sales and communications staff, quality and warehouse managers, researchers, laboratory chiefs) in the period September 2001 to May 2002. Market surveys, websites, and marketing and advertising materials were also used as a cross-check and as information sources. Manufacturers, fast food chains and food items listed in the paper were chosen because of their sales and popularity: more than every second soft drink sold in Denmark is a Coca-Cola and Haribo is the largest manufacturer of bags of sweets. Nestlé is a large confectionery manufacturer and Lion Bar is one of their popular chocolate bars. Frisko is one of the two largest ice cream companies in Denmark and Magnum Classic is one of the best-selling ice creams. Half of all crisps eaten are potato chips and Estrella is one of two leading potato chips manufacturers. McDonald's is the biggest and best-selling fast food restaurant in Denmark $^{15-20}$.

\section{Study 3: Added sugars from commercial foods}

Development in portion sizes of commercial foods was related to data on intakes and sales of sugar-sweetened soft drinks, sweets, chocolate and ice cream from two national dietary surveys and from official sales statistics in the same time period. The nation-wide dietary surveys were cross-sectional studies conducted in Denmark in 1985 and 1995. The study population in 1985 was a random sample from the Danish civil registration system, whereas a random sample stratified by age and gender was drawn from the same civil registration system in 1995. The surveys included a total of 2242 adults (15-80 years) in 1985 and 1837 adults (15-80 years) and 1261 children (1-14 years) in 1995. The response rates in 1985 and 1995 were $76 \%$ and $66 \%$, respectively. Dietary information was obtained by personal interview using the dietary history method in 1985 , and by a 7 -day dietary record with precoded alternatives for the most common foods eaten in the 1995 survey. Food models, photos and household measures were used to estimate portion sizes $^{21,22}$. Both the dietary history method and the 7-day dietary record have been validated against nitrogen urinary excretion in a pilot 
study. The results indicate that energy intake reported in the nation-wide surveys is valid according to the cut-off limit proposed by Goldberg et $a l^{23,24}$.

Information about sales of sugar-sweetened soft drinks, sweets, chocolate and ice cream (1975-99) came from Danish Ministry of Taxation, Central Customs and Tax Administration $^{25}$ and food organisations ${ }^{15}$.

\section{Statistics}

For Study 1, owing to a skewed distribution of the data, the non-parametric Mann-Whitney $U$-test was used to compare age, portion weights, fat and energy contents of low- and full-fat food and meal items. Data for children and adults were pooled to increase statistical power. Twosided $P$-values below 0.05 were considered significant. Data are presented as medians and interquartile ranges. SPSS statistical software version 10.1 for Windows was used. All data from Studies 2 and 3 are presented in a descriptive way. Sales figures in Study 3 are shown as fiveyear averages to show overall trends.

\section{Results}

Study 1: Portion size of low-and full-fat food items The weighed record in 1999 showed that subjects ate and drank significantly more of certain low-fat food and meal items like milk, sauce and sliced cold meat compared with the corresponding food or meal item with a higher fat content (Table 1). When participants chose semi-skimmed milk compared with whole milk they drank $16 \%$ extra $(P=0.013)$. This observation was even more evident with a meal item like sauce. Subjects ate three times larger portion sizes of low-fat sauce $(<5 \%$ fat $)$ at meals in comparison with high-fat sauce $(>15 \%$ fat, $P<0.001)$. The same trend applied to low-fat sliced cold meat used on bread like turkey and chicken in contrast to a high-fat variant like salami $(P=0.021)$. A comparable pattern was seen for pork, although it did not reach significance. As a result participants ate almost the same amount of energy and fat when they chose low-fat food and meal items, with the exception of sliced cold meat (energy and fat) and milk (fat) (Table 1). No significant differences were seen by age between the low- and high-fat food groups.

\section{Study 2: Size of commercial foods}

Our research indicated that sugar-sweetened beverages and confectionery like bags of sweets, chocolate bars, ice creams, etc. have increased in size by $20-100 \%$ since the 1960s, and in particular in the last 10 years (Table 2). The enlargement in package size of pre-packed confectionery can be demonstrated by using Haribo as an example. Haribo launched their first economic bag of sweets ( $150 \mathrm{~g}$ ) in 1976. Four years later $200 \mathrm{~g}$ (Mammut) bags were introduced and in 1991 the first $400 \mathrm{~g}$ package was launched. The expanding trend has also been observed for other snack food items like potato chips, where the $300 \mathrm{~g}$ package is the best-selling bag today with regard to tonnage ${ }^{16}$. All food items shown have increased in weight

Table 1 Average portion size of selected food items low and high in fat, according to the weighed food record, $1999(n=180)$. Fat and energy content are based on recipes of actual weights. Data are shown as medians and interquartile ranges

\begin{tabular}{|c|c|c|c|c|}
\hline & \multicolumn{2}{|c|}{ Low-fat food/meal item } & \multicolumn{2}{|c|}{ High-fat food/meal item } \\
\hline & Number† & & Number† & \\
\hline Milk & $(n=98)$ & & $(n=22)$ & \\
\hline Size (g) & & $207(157-250)$ & & $179^{*}(123-200)$ \\
\hline Fat $(\mathrm{g})$ & & $3.3(2.5-4.0)$ & & $6.2^{\star \star \star}(4.3-7.0)$ \\
\hline Energy (kJ) & & $421(320-510)$ & & $475(327-532)$ \\
\hline Age (years) & & $22(11-35)$ & & $10(6-55)$ \\
\hline Sauce & $(n=16)$ & & $(n=100)$ & \\
\hline Size (g) & & $192(86-283)$ & & $55^{\star \star \star}(28-95)$ \\
\hline Fat $(\mathrm{g})$ & & $8.7(3.9-12.9)$ & & $8.3(4.3-41.4)$ \\
\hline Energy (kJ) & & $563(254-831)$ & & $393(204-683)$ \\
\hline Age (years) & & $23(15-35)$ & & $29(13-57)$ \\
\hline Sliced cold meat & $(n=32)$ & & $(n=77)$ & \\
\hline Size $(g)$ & & $21(15-30)$ & & $16^{*}(11-23)$ \\
\hline Fat $(\mathrm{g})$ & & $0.7(0.5-1.0)$ & & $7.0^{\star \star \star}(4.8-10.1)$ \\
\hline Energy (kJ) & & $104(74-147)$ & & $312^{\star \star \star}(215-449)$ \\
\hline Age (years) & & $22(11-27)$ & & $23(12-45)$ \\
\hline Pork & $(n=26)$ & & $(n=32)$ & \\
\hline Size (g) & & $114(73-143)$ & & $91(50-160)$ \\
\hline Fat $(\mathrm{g})$ & & $12.8(8.2-16.1)$ & & $15.2(8.3-26.6)$ \\
\hline Energy (kJ) & & $858(549-1076)$ & & 874 (475-1534) \\
\hline Age (years) & & $39(23-61)$ & & $38(18-59)$ \\
\hline
\end{tabular}

†The discrepancy between the number of participants in the weighed record 1999 and the number of subjects reporting portion size of low- and high-fat food and meal items is due to the circumstance that not all participants have drunk milk and eaten sauce, sliced cold meat and pork in the recording period.

${ }^{\star}, P<0.05 ;{ }^{\star \star \star}, P<0.001$ 
Table 2 Trends in portion sizes of some very popular sugar-sweetened beverages and confectionery and snacks during the last 40 years in Denmark ${ }^{19,26,27}$ (personal communications)

\begin{tabular}{lcl}
\hline & Weight/volume* $\left(\mathrm{g} / \mathrm{ml}^{*}\right)$ & Year of introduction-termination \\
\hline Soft drinks & $190^{*}$ & $1959-1972$ \\
Coca-Cola & $250^{*}$ & $1972-$ \\
& $350^{*}$ & $1961-1988$ \\
& $500^{*}$ & $1980-$ \\
& $1000^{*}$ & $1971-1994$ \\
& $1500^{*}$ & $1991-$ \\
Sweets & 57 & $1993-2001$ \\
Saltbomber, Haribo & 90 & $1999-$ \\
Chocolate & 45 & $1990-$ \\
Lion Bar, Nestlé & 69 & $1996-$ \\
Ice cream & & $1957-1989$ \\
$\quad$ Hawaii, Frisko & $90^{*}$ & $1989-$ \\
Magnum Classic, Frisko & $120^{*}$ & $1959-$ \\
Potato chips & 100 & $2001-$ \\
Taffelchips, Estrella & 200 & $1969-2000$ \\
& 250 & $2000-$ \\
& 300 &
\end{tabular}

or volume only, while the concentration of energycontributing nutrients has remained the same ${ }^{28}$.

McDonald's meals are used to illustrate the development in portion sizes of Danish fast food restaurants. In 1990 McDonald's medium and large meals were introduced, whereas the mega meal was available in 2001. A mega-size McDonald's meal contains half of the habitual daily energy intake, most of the recommended fat and all of the recommended added sugars for an average adult (Table 3).

\section{Study 3: Added sugars from commercial foods}

Both dietary survey data and sales figures revealed a sharp increase in the average consumption of sugar-sweetened soft drinks since the mid-1980s (Fig. 1a). According to nation-wide dietary surveys, the intake of sugarsweetened soft drinks more than doubled from 1985 to 1995 ( 44 vs. $\left.107 \mathrm{~g} \mathrm{day}^{-1}\right)^{21,22}$. Sales figures from the Danish Brewers' Association illustrated a similar pattern although the rise was less pronounced (1985-89: 75 vs. 1995-99: $\left.141 \mathrm{~g} \mathrm{day}^{-1}\right)^{15}$. Before the 1990s, per capita sales of sugar-sweetened soft drinks seemed to have been more uniform at around $70-75 \mathrm{~g} \mathrm{day}^{-1}$. From the mid-1980s to late 1990 s, a $20 \%$ increase was observed in intakes and sales of confectionery like sweets, chocolate and ice cream, even though the intake reported is much lower in dietary surveys (1985: 17.5 vs. 1995: $20.8 \mathrm{~g} \mathrm{day}^{-1}$ ) compared with sales figures (1985-89: 46 vs. 1995-99: $\left.58 \mathrm{~g} \mathrm{day}^{-1}\right)^{15,21,22,25}$. Since 1975 there has been a continuous rise in the sale of confectionery, and $50 \%$ more is sold today than 25 years ago (Fig. 1b).

\section{Discussion}

\section{Portion size of low- and full-fat food items}

Data from the 4-day weighed record suggest that subjects ate and drank significantly more when they chose low-fat food and meal items, compared with their counterparts who chose food and meal items with a higher fat content. Hence, it looks like some people may compensate the dilution in energy by increasing the total amount of low-fat foods consumed. The same phenomenon seems to be

Table 3 Trends in portion size of a McDonald's meal (Big Mac, french fries and Coca-Cola) in Denmark ${ }^{29}$

\begin{tabular}{|c|c|c|c|c|c|}
\hline & $\begin{array}{l}\text { Weight/volume* } \\
\left(\mathrm{g} / \mathrm{ml}^{*}\right)\end{array}$ & $\begin{array}{l}\text { Year of } \\
\text { introduction }\end{array}$ & $\begin{array}{l}\text { Energy } \\
(\mathrm{kJ})\end{array}$ & $\begin{array}{c}\text { Fat } \\
\text { (g; \% of energy) }\end{array}$ & $\begin{array}{l}\text { Added sugars } \\
\text { (g; \% of energy) }\end{array}$ \\
\hline \multicolumn{6}{|l|}{ McDonald's meal medium } \\
\hline Big Mac† + medium french fries + medium Coca-Cola & $209+116+400^{*}$ & $1990-$ & 4115 & $42 ; 39$ & $44 ; 18$ \\
\hline $\begin{array}{l}\text { Big Mact + large french fries + large Coca-Cola } \\
\text { McDonald's meal mega }\end{array}$ & $209+164+500^{*}$ & $1990-$ & 4811 & $49 ; 39$ & $55 ; 19$ \\
\hline $\begin{array}{l}\text { Big Mac } \dagger+\text { mega french fries }+ \text { mega Coca-Cola } \\
\text { Recommended intake }\end{array}$ & $209+180+650^{*}$ & $2001-$ & $\begin{array}{c}5262 \\
10000 \ddagger\end{array}$ & $\begin{array}{l}51 ; 37 \\
80 ; 30\end{array}$ & $\begin{array}{l}72 ; 23 \\
60 ; 10\end{array}$ \\
\hline
\end{tabular}

† The best-selling burger at McDonald's ${ }^{20}$.

¥ Mean daily energy intake for a Danish adult $15-80$ years of age in $1995^{22}$. 


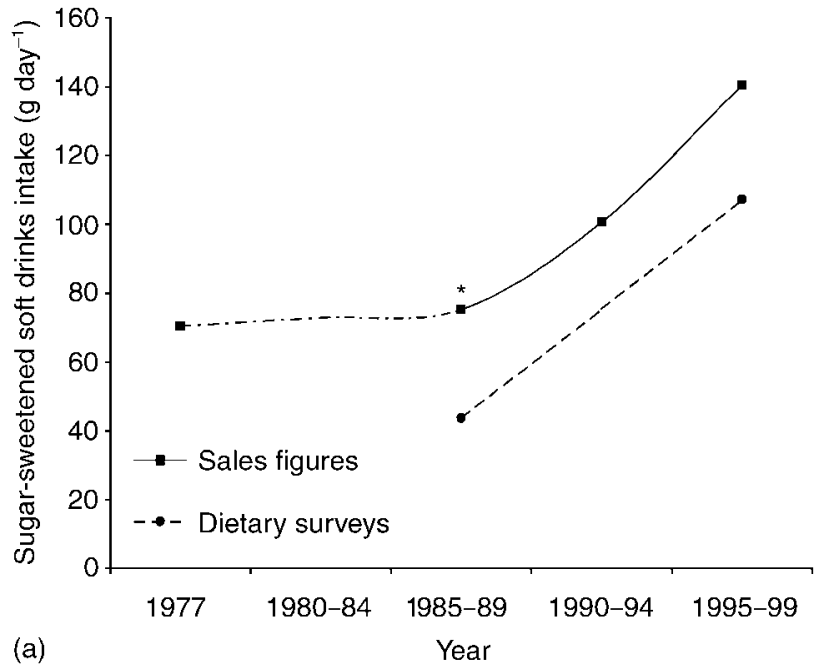

of the sliced cold meat eaten in Denmark is produced industrially, and slices of the different types of meat and salami weigh almost the same $(12 \mathrm{~g})^{33}$. In any case, if people eat low-fat food and meal items ad libitum there seems to be an obvious risk of over-consumption and weight gain, because many individuals believe low-fat foods give them a licence to eat more ${ }^{4}$.

A meta-analysis of longer lasting intervention studies conducted by Astrup et al. ${ }^{34}$ has shown that ad libitum low-fat diets with a mean proportion of energy from fat of $27.5 \%$ resulted in a modest average weight loss of $3.2 \mathrm{~kg}$, primarily by lowering the total energy intake. Even though a weight loss of this size could have a huge impact on a population level, reducing dietary fat probably has more significance in preventing further weight gain than in reversing obesity ${ }^{4,35}$. This belief is also supported by the existence of the American paradox in several countries, where a lower fat content in the diet has not led to a decrease in the prevalence of overweight and obesity ${ }^{1,2,36}$. However, today, when a large part of the population has a sedentary lifestyle, the significance of the fat content in the diet still needs to be stressed because many people have a lower fat tolerance, as energy balance is determined by the interaction between level of physical activity and dietary fat content ${ }^{8,35,37,38}$. This implies that people with a typical level of physical activity nowadays can reach a positive energy balance, even with a fairly low fat percentage in their diet.

Energy intake seems to have been remarkably stable over time, in spite of a reduction in fat intake ${ }^{15,21,22}$. However, impaired data collection in food balance sheets in the last decade and methodological differences in the two nation-wide dietary surveys could bias these results ${ }^{15,21,22,24}$. Still, one likely explanation for maintaining a high energy intake, taking the lower needs into consideration $^{1}$, may be the increasing trend in portion size of low-fat foods. This may be one of the causes of overconsumption, enhancing the prevalence of obesity in the population. Another possible explanation might be that the decrease in fat and energy intakes has been set off by an increased sedentary lifestyle. As a consequence of the fact that sedentary work has doubled from 1985 to 1995 , energy expenditure now appears to be lower, since leisure-time physical activity has not increased proportionally ${ }^{1}$. Thus, it looks as if Danes are eating the same despite their lower nutritional needs.

\section{Size of commercial foods}

Our findings indicate that larger package and portion sizes of energy-dense beverages and confectionery and fast food meals, rich in fat and/or added sugars, have been introduced over time, in particular in the last 10 years. However, it should be stressed that there are certain limitations to these findings. Portion sizes of commercial foods change constantly, so that food manufacturers and fast food restaurants might supply inaccurate weights/ 
volumes and dates. But official statistics on the consumption of soft drinks, confectionery and fast food are nonexistent in Denmark, therefore it is necessary to seek alternative sources of information like manufacturers and fast food restaurants. Still, sales statistics ${ }^{15,25}$ support the super-sizing commercial food trend, which is also prevalent in the United States, where portion sizes of foods are much larger than standard portion sizes developed by the US Department of Agriculture and the US Food and Drug Administration ${ }^{10-13}$. In the USA the trend towards larger portion sizes started in the 1970s and has accelerated since then ${ }^{10}$. An energy-dense diet, rich in fat and/or added sugars, is one the main factors responsible for an increasing energy intake and hence the promotion of obesity. Short-term energy intake is influenced by energy density of food in both lean and obese adults ${ }^{39}$.

Expanding soft drinks containers have most probably contributed to the escalating intake in the last decade. Of the daily intake, more than $50 \%$ is considered to be sugarsweetened $^{15,21,22}$, corresponding to $110-140 \mathrm{~g}$ per person per day (Fig. 1a). Forty years ago the only soft drinks containers available on the market in Denmark were small and medium, holding 190 and $350 \mathrm{ml}$; now these bottles have enlarged to 250 and $500 \mathrm{ml}$ (Table 2). The same pattern is seen for the 'family size' bottle: handy and antibreaking plastic bottles that weigh less, making transportation and drinking easier, have today replaced most of the glass bottles used formerly. The volume of Coca-Cola sold in Denmark doubled in the 1990s when $500 \mathrm{ml}$ and $1500 \mathrm{ml}$ plastic bottles were introduced, lending support to the belief stated above, and the best-selling container size in terms of volume today is the $500 \mathrm{ml} \mathrm{Coca-Cola}^{15,16}$.

Development in the package size of confectionery (Table 2) is paralleled by a more than $50 \%$ increase in the sales of sweets, chocolate and ice cream per capita in the past 25 years, supporting the validity of the changes in package sizes informed by the manufacturers (Fig. 1b). Standard bags of sweets and chocolate bars weighed 40$50 \mathrm{~g}$ a few years ago; now they are super-sized and weigh 70-100 g, and contain twice as much energy and added sugars as before. It is even possible to buy mega-sized bags of sweets weighing 200-300 g. The increase in package sizes of, for instance, Haribo's sweets products has taken place from 1976 to the 1990s, supporting the super-size hypothesis. Likewise, Frisko increased their sales of ice cream considerably after the introduction of the large ice cream Magnum in $1989^{17}$, so it appears that manufacturers launch new super-sized packages as a means to draw attention to a product and raise its sales ${ }^{10}$. Alongside the super-sizing trend smaller package sizes of confectionery and snacks, weighing from 8 to $40 \mathrm{~g}$ and primarily intended for smaller children, have also been launched, but the sales amount to only a minor part of the total tonnage ${ }^{16}$

Today, mega-size menu items are common in many fast food restaurants even in Denmark. When McDonald's opened their first restaurant in 1981, the meal concept did not exist at all $^{40}$. Ten years later it was possible to buy both medium and large meals, and in 2001 mega meals were introduced, adding $1 \mathrm{MJ}$ extra to the energy- and fat-dense medium meal, which is now seen as the smallest, but still the best-selling, McDonald's meal (Table 3).

Even if the Danes are not a nation of fast food eaters, fast food restaurants have been on the rise more than ever in the last 10 years. In year 2000 McDonald's had a turnover of 167 million Euro, which corresponds to almost five medium meals per person ${ }^{20}$. Yet, data from the 1995 dietary survey showed that $75 \%$ of all Danes eat outside the home less than two times each month, and more than $50 \%$ eat out hardly once a month ${ }^{15}$. Other and more recent Danish surveys confirm this trend ${ }^{41,42}$.

Increasing meal size in fast food restaurants very likely plays a part in the growing portion distortion in the population, but the significance of fast food meals in relation to the increasing prevalence of obesity in Denmark seems to be modest, taking the few eating occasions at take-aways, restaurants, etc. into account ${ }^{15,41,42}$. Nevertheless, the importance of fast food in the obesity epidemic should not be neglected for younger people, who are the most frequent consumers of fast food ${ }^{41-43}$. In the USA fast foods contribute five times more calories to children's diets today than 20 years ago ${ }^{44}$, and the same trend can most likely be expected in Europe $^{15}$.

\section{Added sugars from commercial foods}

Sugar-sweetened soft drinks and sweets, chocolate and ice cream are the main sources of added sugars, contributing about half of the daily intake $\mathrm{e}^{22}$. As subjects tend to underreport sugar-rich food items like soft drinks and confectionery $^{45}$, sales statistics are probably the most reliable data in this context, since they are not prone to underreporting bias like the individual-based dietary surveys $^{31}$, and waste and spoilage appear to be limited. The problem is clearly illustrated by Fig. $1 \mathrm{a}$ and $\mathrm{b}$, where the highest degree of underreporting seems to be prevalent for confectionery. According to sales figures and food balance sheets, it appears that the intake of added sugar has increased in the past 15 years ${ }^{15,25}$.

The highest consumers of added sugars are 7- to 14year-old children, who eat 50\% more added sugars than adults, and the diets of only one-quarter of 4- to 14-yearold children are below the recommended maximum of $10 \%$ of energy ${ }^{22,30,46}$. Compared with adults, children consume twice the amount of soft drinks and confectionery $^{22}$. A high intake of added sugars has several adverse consequences like dilution of nutrient density in the diet, and increased risk of caries and obesity ${ }^{46-49}$. If children and adults have continued to drink the same number of sugar-sweetened beverages and eat the same number of bags of sweets, chocolate bars, ice creams, etc. as before, 
then the super-sizing trend could be one of the explanations for the rising number of overweight and obese children and adults seen in Denmark during past decades ${ }^{1,14,50}$, especially in an environment where physical activity is declining ${ }^{1,14}$.

\section{Dietary guidelines}

The current dietary advice in Denmark consists of seven evidence- and action-based dietary guidelines prepared by the official authorities in collaboration with research nutritionists. Two of the seven dietary guidelines focus on cutting down on fat and added sugars, although the guidelines are not specific in terms of amounts ${ }^{51}$.

Many people seem to have got the wrong idea about the low-fat health message without paying attention to the total amount of food consumed. As underlined in the present study, choosing food and meal items low in fat does not allow people to eat all they want since this will also increase the energy intake. Hence, it is not only a matter of the kind of food a person eats, but also the amount of food eaten ${ }^{3,4}$. One of the reasons why many Danes have so far ignored portion size can be ascribed to the fact that none of the official dietary guidelines emphasises the significance of the amount of food eaten.

Misinterpretation of the low-fat health message is presumably also caused by a lack in public nutritional education, which so far has not focused enough on portion size or amount of food. With the present obesity situation in mind, perhaps new guidelines and public campaigns should be made regarding the quantity of food to eat, since the development of standard portion sizes would be useful for dietary guidance ${ }^{10-12}$. People need to be aware that control of portion size is just as important, if not more so, as cutting down on fat to maintain stable body weight.

\section{Conclusion}

Larger portion sizes of foods low in fat and commercial energy-dense foods and beverages could be an important factor in maintaining a high energy intake, causing overconsumption and enhancing the prevalence of obesity in the population. In light of this development, portion size ought to take a central place in dietary guidelines and public campaigns.

\section{References}

1 Matthiessen J, Andersen NL, Ovesen L. The role of diet and physical activity in the increasing prevalence of overweight and obesity in Denmark 1985-1995 [in Danish with an English summary]. J. Dan. Med. Assoc. 2001; 163: 2941-5.

2 Heini AF, Weinsier RL. Divergent trends in obesity and fat intake patterns: the American paradox. Am. J. Med. 1997; 102: $259-64$.

3 Allred JB. Too much of a good thing? An overemphasis on eating low-fat foods may be contributing to the alarming increase in overweight among US adults. J. Am. Diet. Assoc. 1995; 95: 417-8.

4 Rolls BJ, Miller D. Is the low-fat message giving people a license to eat more? J. Am. Coll. Nutr. 1997; 16: 535-43.

5 Rolls BJ, Engell D, Birch LL. Serving portion size influences 5-year-old but not 3-year-old children's food intakes. J. Am. Diet. Assoc. 2000; 100: 232-4.

6 Edelman B, Engell D, Bronstein P, Hirsch E. Environmental effects on the intake of overweight and normal-weight men. Appetite 1986; 7: 71-83.

7 Prentice A, Jebb SA. Obesity in Britain: gluttony or sloth? Br. Med.J. 1995; 311: 437-9.

8 Astrup A. Macronutrient balances and obesity: the role of diet and physical activity. Public Health Nutr. 1999; 2: $341-7$.

9 Hess MA. Portion Photos of Popular Foods. The American Dietetic Association and Center for Nutrition Education, University of Wisconsin-Stout, 1997.

10 Young LR, Nestle M. The contribution of expanding portion sizes to the US obesity epidemic. Am. J. Public Health 2002; 92: $246-9$.

11 Young LR. Portion sizes in the American food supply: issues and implications. Dissertation, New York University, New York, 2000

12 Young LR, Nestle M. Portion sizes in dietary assessment: issues and policy implications. Nutr. Rev. 1995; 53: 149-58.

13 Peregrin T. A super-sized problem: restaurants chains piling on the food. J. Am. Diet. Assoc. 2001; 101: 620.

14 Kjøller M, Rasmussen NK. Danish Health and Morbidity Survey 2000 \& Trends since 1987 [in Danish with an English summary]. Copenhagen: Statens Institut for Folkesundhed (National Institute of Public Health), 2002.

15 Fagt S, Trolle E. The Supply of Food in 1955-1999. Development in Danish Diet - Consumption, Food, Purchases and Eating Habits [in Danish]. FødevareRapport 2001:10. Copenhagen: Fødevaredirektoratet (Danish Veterinary and Food Administration), 2001.

16 ACNielsen AIM A/S. ScanTrack (Markedsundersøgelser af dagligvarehandlen $i$ Danmark) [Market Surveys of the Grocery Trait in Denmark]. Copenhagen: ACNielsen AIM A/S, 2002

17 Vilstrup Research. Konkurrent-undersøgelse på impulsismarkedet [Competitor Survey on Impulse Ice-market]. Copenhagen: Vilstrup Research, 2001.

18 Okholm B, Jakobsen J, Saxholt E. Chipsprodukter. Markedsundersøgelse [Crisp Products. Market Survey]. Internal Report. Arhus: Levnedsmiddelstyrelsen (National Food Agency), 1997.

19 Danish Estrella A/S. Kartoflens historie [History of the Potato, online]. Available at http://www.estrella.dk. Accessed 8 May 2002.

20 McDonalds restaurant-keepers in Denmark [in Danish]. McDonald's Avisen [McDonald's Newspaper], Summer 2001.

21 Haraldsdóttir J, Holm L, Jensen JH, Møller A. Dietary Habits in Denmark 1985. 1. Main Results [in Danish with an English summary]. Publication No. 136. Copenhagen: Levnedsmiddelstyrelsen (National Food Agency), 1986.

22 Andersen NL, Fagt S, Groth MV, Hartkopp HB, Møller A, Ovesen L, Warming DL. Danish Dietary Habits 1995. Main Results [in Danish with an English summary]. Publication No. 235. Copenhagen: Levnedsmiddelstyrelsen (National Food Agency), 1996.

23 Goldberg GR, Black AE, Jebb SA, Clo TJ, Murgatroyd PR, Coward WA, et al. Critical evaluation of energy intake using fundamental principles of energy physiology: 1. Derivation of cut-off values to identify underreporting. Eur.J. Clin. Nutr. 1991; 45: 569-82.

24 Groth MV, Fagt S. Danish Dietary Habits 1995. Technical Report 1. Organization, Implementation and Data Quality of the Dietary Survey 1995 [in Danish]. Internal Report. 
Copenhagen: Levnedsmiddelstyrelsen (National Food Agency), 1995.

25 Told \& Skat (Danish Ministry of Taxation, Central Customs and Tax Administration). Chokoladeafgift [Tax on chocolate]. In: Rapport om gransehandel [Report on Borderline Trading], 2000 [online]. Available at http://www.skat.dk/ pub1/rapporter/graensehandel/kap12.htm. Accessed 8 May 2002.

26 Coca-Cola Company Denmark. Coca-Cola historier [CocaCola histories]. Coca-Cola Magazine [online]. Available at http://www.cocacola.dk. Accessed 8 May 2002.

27 Frisko. Historien om Frisko - Fortalt med tidens isskilte [Frisko bistory - told by the signs of ice at the time, online]. Available at http://www.frisko.dk. Accessed 8 May 2002.

28 Møller A, Saxholt E. Levnedsmiddeltabeller [Food Composition Tables], 4th ed. Copenhagen: Levnedsmiddelstyrelsen (National Food Agency), 1996

29 McDonalds restaurant-keepers in Denmark [in Danish]. McDonald's Avisen [McDonald's Newspaper], Autumn 2001.

30 Nordiska Ministerrådet (Nordic Council of Ministers). Nordiska Näringsrekommendationer 1996 [Nordic Nutrition Recommendations, in Swedish]. Nord 1996:28. Copenhagen: Nordisk Ministerråd, 1996.

31 Harnack LJ, Jeffery RW, Boutelle KN. Temporal trends in energy intake in the United States: an ecological perspective. Am.J. Clin. Nutr. 2000; 71(6): 1478-84.

32 Knuthsen P, Peetz-Schou M. Fat Content in Homemade Sauces [in Danish]. FødevareRapport 2002:5. Copenhagen: Fødevaredirektoratet (Danish Veterinary and Food Adminstration), 2002.

33 Andersen LT, Jensen H, Haraldsdóttir J. Typiske vægte for madvarer [Typical weights for food items]. Scand. J. Nutr 1996; 4(Suppl. 32): S129-52.

34 Astrup A, Grunwald GK, Melanson EL, Saris WH, Hill JO. The role of low-fat diets in body weight control: a meta-analysis of ad libitum dietary intervention studies. Int.J. Obes. Relat. Metab. Disord. 2000; 24: 1545-52.

35 Hill J, Peters J. Environmental contributions to the obesity epidemic. Science 1998; 280: 1371-4.

36 Fogelholm M, Männistö S, Vartiainen E, Pietinen $\mathrm{P}$. Determinants of energy balance and overweight in Finland 1982 and 1992. Int. J. Obes. 1996; 20: 1097-104.

37 Stubbs RJ, Harbron CG, Murgatroyd PR, Prentice AM. Covert manipulation of dietary fat and energy density: effect on substrate flux and food energy intake in men eating ad libitum. Am. J. Clin. Nutr. 1995; 62: 316-29.

38 Stubbs RJ, Ritz P, Coward WA, Prentice AM. Covert manipulation of the ratio of dietary fat to carbohydrate and energy density: effect on food energy intake and energy balance in free-living men eating ad libitum. Am. J. Clin. Nutr. 1995; 62: 330-7.

39 Bell EA, Rolls BJ. Energy density of foods affects energy intake across multiple levels of fat content in lean and obese women. Am.J. Clin. Nutr. 2001; 73: 1010-8.

40 McDonald's Denmark A/S. Om McDonald's [About McDonald's, online]. Available at http://www.mcdonalds. dk. Accessed 8 May 2002.

41 Jysk Analyseinstitut A/S. Convenience rapporten'01 [Report on Convenience'01]. Aalborg: Jysk Analyseinstitut A/S, 2001.

42 Perception Research \& Consulting. Danskere og kvalitetsmad [Danes and Quality Food]. Copenhagen: Perception Research \& Consulting, 2001.

43 Fagt S, Groth MV, Andersen NL. Dietary Habits in Denmark 1995, Food and Meals [in Danish with an English summary]. FødevareRapport 2000:06. Copenhagen: Fødevaredirektoratet (Danish Veterinary and Food Administration), 1999.

44 Lin B-H, Guthrie J, Frazao E. American children's diets not making the grade. In: Mentzer Morrison R, ed. Examining the Well-being of Children. Food Review, Vol. 24-2. US Department of Agriculture, Economic Research Service, 2001; 8-17.

45 Johansson L, Solvoll K, Bjorneboe GE, Drevon CA. Underand overreporting of energy intake related to weight status and lifestyle in a nationwide sample. Am.J. Clin. Nutr. 1998; 68: $266-74$

46 Lyhne N, Ovesen L. Added sugars and nutrient density in the diet of Danish children. Scand. J. Nutr. 1999; 43: 4-7.

47 Sundin B, Granath L. Sweets and other sugary products tend to be the primary etiologic factors in dental caries. Scand. J. Dent. Res. 1992; 100: 137-9.

48 Majewski RF. Dental caries in adolescents associated with caffeinated carbonated beverages. Pediatr. Dent. 2001; 23 198-203.

49 Ludwig DS, Peterson KE, Gortmaker SL. Relation between consumption of sugar-sweetened drinks and childhood obesity: a prospective, observational analysis. Lancet 2001; 257: $505-8$

50 Wedderkopp N, Andersen LB, Hansen HS, Froberg K. Childhood obesity, with particular reference to Denmark [in Danish with an English summary]. J. Dan. Med. Assoc. 2001; 163: 2907-12.

51 Forbrugerstyrelsen, Statens Husholdningsråd (National Consumer Agency of Denmark, The Danish Government Home Economics Council). De Syv kostråd [The Seven Dietary Guidelines]. Copenhagen: Forbrugerstyrelsen, 1995. 